\title{
RESENHA
}

\section{HAESBAERT R., NUNES PEREIRA S., RIBEIRO G. (dir.), 2012, Vidal, Vidais: textos de Geografia Humana, Regional e Política, Rio de Janeiro, Bertrad Brasil, 464 p. ${ }^{1}$}

O livro Vidal, vidais: textos de geografia humana, regional e política é uma edição brasileira, enriquecida com excelente aparato crítico, de 25 textos do célebre geógrafo francês Paul Vidal de la Blache (1845-1918), uma parte dos quais está traduzida para o português pela primeira vez. Essa obra nos parece muito útil para conhecer a visão brasiliana da atual geografia francesa, obra ainda mais importante porque os geógrafos destes dois países tiveram historicamente um enlace privilegiado.

O título, aproximando as palavras Vidal, singular, e Vidais no plural, sugere, ironicamente, uma das temáticas que os autores escolheram para estudar o "chefe" da escola francesa da Géographie Humaine e, particularmente, o "caráter dinâmico e múltiplo" (Haesbaert et al., 2012a, p. 14) da sua obra.

O livro participa da redescoberta dos clássicos que caracteriza atualmente a América Latina em geral e o Brasil, em particular, que se distancia da estratégia "iconoclasta" da geografia quantitativa e crítica dos anos 1960 e 1970, sem a pretensão de, por isso, ser nostálgica ou demais reverente.

Atualmente, faz parte do cerne das pesquisas uma recuperação crítica destes clássicos através de um retorno às fontes e de um trabalho sistemático acerca dos textos. Sobre Vidal de la Blache, os organizadores do livro acham que se num certo momento da história disciplinar no Brasil a sua "caracterização dominante era a de um geógrafo empirista, descritivo e preocupado basicamente com a escala regional, a pesquisa direta no material publicado nos Annales de Géographie, bem como em outros periódicos, mostra-nos um Vidal bem diferente" (Haesbaert et al., 2012b, p. 13).

\footnotetext{
${ }^{1}$ Esta resenha foi publicada em versão francesa na revista Cybergeo : European Journal of Geography http://cybergeo.revues.org/
} 
Utilizando as ferramentas intelectuais da arqueologia dos saberes de Michel Foucault, os organizadores recusam, contudo, a canonização de Vidal, porque preferem focalizar-se na utilização dos saberes na construção de um discurso científico. Assim, os organizadores chegam a definir o discurso vidaliano como "uma perspectiva científica de vanguarda" (Haesbaert et al., 2012c, p. 15) em relação ao ambiente intelectual francês da sua época.

Aberto por um prefácio de Paul Claval, seguido por uma introdução geral dos organizadores, o livro compõe-se de três partes: "Geografia humana", "Geografia regional" e "Geografia política", cada uma acompanhada por uma introdução crítica de um dos autores.

A primeira parte, "Geografia humana", é introduzida pelo texto de Guilherme Ribeiro, "Geografia humana: fundamentos epistemológicos duma ciência". Os textos traduzidos nessa seção são o Prefácio ao Atlas Vidal-Lablache (1894) ; O princípio da geografia geral (1896); Aula inaugural do curso de geografia (1899) ; As condições geográficas dos fatos sociais (1902); A geografia humana: suas relações com a geografia da vida (1903) ; Da interpretação geográfica das Paisagens (1908); e Os gêneros de vida na geografia humana (1911).

No seu comentário, Ribeiro justifica primeiro a escolha dos textos dessa seção, acreditando que são esses os escritos teóricos sobre os quais Vidal de la Blache funda a sua concepção da geografia humana como disciplina e onde ele "promove uma discussão teórico-metodológica" (Haesbaert et al., 2012d, p. 24), que o autor pretende analisar nos seus pontos salientes e na ordem cronológica da sua aparição no discurso vidaliano.

O primeiro conceito que Ribeiro aborda é a afirmação vidaliana do princípio da unidade terrestre que não é, no entanto, uma afirmação de uniformidade, porque esse princípio define as articulações necessárias entre o Todo e as suas Partes. Diante disso, depreende-se que não se pode estudar o primeiro independentemente das segundas, e as segundas sem o primeiro. Neste sentido, Ribeiro destaca a dívida de Vidal de la Blache com a geografia de Alexander von Humboldt e de Carl Ritter, questão citada muitas vezes na literatura francófona dos últimos anos (Robic, 2000; 2009), e destaca também a presença dos autores citados na Aula inaugural do curso de geografia, de Oscar Peschel e Élisée Reclus (Haesbaert et al., 2012e, p. 27).

Analisando o artigo A Geografia humana, publicado na Revue de synthèse, Ribeiro problematiza a definição vidaliana dos limites 
disciplinares da geografia. Conhecemos os debates que se desenvolveram no entorno dessa revista, sobretudo entre os geógrafos e os sociólogos durkheimianos (Mucchielli e Robic, 1995), mas sabemos também que entre Henri Berr e os representantes das disciplinas envolvidas existia uma aliança factual contra a histoire événementielle, que alguns autores acreditam hoje ser um inimigo "pura e simplesmente inventado" (Prochasson, 1997, p. 69).

É sobre a relação entre geografia humana e história que Ribeiro exprime alguns julgamentos que nos parecem bastante representativos da atual abordagem brasileira da história da geografia, mais atenta às questões da colaboração interdisciplinar que à luta e à concorrência entre disciplinas. Consoante Ribeiro, Vidal de la Blache considera, também por sua formação de historiador, que "a geografia é uma disciplina histórica" (Haesbaert et al., 2012f, p. 32). O ensaio destaca, depois, a importância, na estratégia vidaliana, da ideia de paisagem em relação à centralidade do trabalho de campo. Enfim, Ribeiro termina definindo o conceito de gênero de vida como a última representação de uma geografia atenta aos métodos das ciências naturais e ao evolucionismo, sem derrogar ao princípio do estudo conjunto da humanidade e da natureza. Uma geografia consciente, nós acrescentamos, da lição da filosofia natural do século XIX.

A segunda parte, intitulada "Geografia Regional" é introduzida pelo texto "Vidal e a Multiplicidade de Abordagens Regionais", de Rogério Haesbaert. Os textos de Vidal de la Blache traduzidos nessa seção são: As divisões regionais do território francês (partes I, II e IV) (1888); Estradas e Caminhos da França Antiga (1902); Os pays da França (1904); As regiões francesas (1910); A relatividade das divisões regionais [1911]; A Evolução da População na Alsácia-Lorena e nos departamentos limítrofes [1916]; e A renovação da vida regional (1917).

Haesbaert procura questionar alguns limites em que foram moldadas as interpretações vidalianas no Brasil. A primeira delas seria a oposição entre o possibilismo e o determinismo que, segundo o autor, é equivocada. A segunda, mais importante para o efeito desta seção, é o enquadramento de uma região vidaliana sob apenas um único princípio de agrupamento regional (as regiões da relação homem-meio), e em uma escala.

Segundo Haesbaert, tais leituras brasileiras são fruto da circulação de livros como o de Lucien Febvre, A terra e a evolução humana, de um lado, e, de outro, A Geografia serve antes de mais nada para fazer a guerra, de Yves Lacoste, fontes cujo público brasileiro está habituado ao contato e que são utilizadas correntemente em nossos currículos, mais até do que o 
próprio Vidal de la Blache. Haesbaert tem o mérito de dialogar com a história da Geografia produzida no Brasil, com os "lugares-comuns" lentamente conformados ao longo de sua história.

Portanto, a linha mestra desse comentário de Haesbaert diz respeito à inexistência de "uma região vidaliana", para o qual o jogo do singular e do plural, presente no título do livro, mais uma vez bem caracteriza as oposições de interpretação a que estão sujeitas as leituras vidalianas. Consoante o autor, não se trata de "uma região", mas "regiões", concebidas e entrecruzadas num jogo de escalas complexo. Nesse contexto, as contribuições de Marie-Claire Robic (2000 e 2004) e Marie-Vic OzoufMarignier (2000), produzidas na França, têm diálogo franco com as letras lá vertidas, de forma que as redes de trocas acadêmicas entre o Brasil e a França parecem ter mais uma vez se encontrado.

Para Haesbaert, o conceito de região foi sendo continuamente elaborado pelo geógrafo francês e a seleção de textos, cronologicamente organizada, procura demonstrar esta assertiva. O esforço de classificação dessa questão regional em fases de produção acadêmica de Vidal de la Blache, engessaria o debate se o autor não tivesse tido o cuidado de salientar que essas definições cruzam-se em muitos dos trabalhos deste geógrafo.

Em uma primeira fase vidaliana, fala-se na inspiração da geologia de Vidal de la Blache, na rejeição das divisões político-administrativas e na valorização das unidades fisiográficas. Seguidamente, o autor disserta sobre uma fase de transição, em que se observa que as bases naturais são enfrentadas em sua relação de adaptação do homem ao meio; e por fim, uma terceira fase em que aparece uma região econômica, emprestando conceitos como o de "modalidade", do geógrafo inglês Halford Mackinder cujo exemplo mais evidente é a região lionesa. Haveria uma quarta fase, em que Vidal enfrenta a questão regional a partir das redes de circulação e da importância da divisão do trabalho? Essa hipótese poderá ser lançada para novas pesquisas. Mas é de extrema importância também o comentário de Haesbaert que procura relativizar tais classificações e periodizações.

Contudo, seria desejável dispor de uma tradução integral do texto As divisões fundamentais do território francês, incluindo os trechos em que os autores atribuem-no como sendo da geografia física. Alegado o caráter "empírico-descritivo", achamos que esses textos contribuiriam para a compreensão, no Brasil, do princípio da regionalização de Vidal de la Blache onde as regiões, renovadas pela modernização, compreendem um 
princípio de agrupamento geográfico que não exclui o papel das regiões naturais e das suas polaridades tradicionais.

A terceira parte é denominada "Geografia Política" e é introduzida pelo texto de Sergio Nunes Pereira sobre os "Estados, nações e colonialismo: traços da geografia política vidaliana". Os textos de Vidal traduzidos nessa seção são: Estados e Nações da Europa em torno da França (extratos) (1889), A zona fronteiriça entre a Argélia e o Marrocos conforme novos documentos (1897), A Geografia Política; a propósito dos escritos do Sr. Friedrich Ratzel (1898), O contestado franco-brasileiro (1901); A missão militar francesa no Peru (1906), A Colúmbia Britânica (1908), A carta do mundo ao milionésimo (1908); A conquista do Saara (1911), Sobre o princípio de agrupamento na Europa Ocidental (1917).

Assim como o comentário da seção anterior, nesta introdução, Pereira busca desconstruir a ideia de que não existiria um fundo político na obra de Vidal de la Blache e que, nesse quesito, ele estaria em franca oposição com as contribuições de Ratzel. Nada mais equivocado, argumenta o autor.

Mas se é evidente que existem preocupações políticas que perpassam o conjunto da obra, a ideia de que Vidal de la Blache se engaja fidedignamente nas questões do Estado tem a mesma força? As escolhas dos textos traduzidos não parecem confirmar essa hipótese, uma vez que as contribuições "geopolíticas" deste geógrafo são esparsas e foram publicadas mais permanentemente em forma de notas, nas seções de correspondência dos Annales de Géographie. Nesse sentido, Nunes Pereira contesta a ideia de Y. Lacoste de um Vidal de la Blache pretendido "geopolítico" na França de Leste, e lhe parece mais apropriado falar que Vidal combina sua geografia política com sua geografia humana, à medida que amadurecem suas concepções sobre a presença do homem na Terra, transitando entre as duas categorizações de forma a quase não se observar diferenças até que fosse definitivamente escolhida a expressão "Geografia Humana". Pereira foi bem atento a tais sutilezas do discurso. Ele nos diz, por exemplo, que a obra de Vidal não se resume à escala do Estado e que fala frequentemente em "agrupamentos humanos", "povos" e "grupos étnicos". Ademais, ele hesita em usar o vocábulo "geopolítica" para classificar a contribuição de Vidal de la Blache.

$\mathrm{O}$ autor percebeu o quanto a evolução do pensamento político na Alemanha, notadamente na figura de Friedrich Ratzel, influenciou as contribuições vidalianas, ainda que tais concepções possuam diferenças importantes. A passagem da "geografia política" para a "antropogeografia" 
parece uma posição que foi incorporada por Vidal de la Blache. Mesmo assim, o livro États et Nation de l'Europe, publicado em 1889, parece já admitir, consoante Pereira, as contribuições do geógrafo alemão, ainda que em sua redação estejam refletidas também as antigas geografias políticas "enciclopedistas" da antiga tradição francesa que já pululavam entre os diletantes dos congressos de geografia - análise original e controversa que nos fornece o autor.

É manifesto, contudo, que às concepções geográficas de Vidal de la Blache se ligam "as tarefas estratégicas e de controle do território desenvolvidas por Estados em nível nacional, continental, ou, quando europeus, com relação a domínios do ultramar" (Haesbaert et al., 2012g, p. 338) e que a sua teoria está imbuída de uma visão política a serviço do colonialismo francês. Mesmo que estas tomadas de posições não estejam, a nosso ver, no centro da cena do discurso científico do autor, para Pereira, elas estão presentes e não se pode julgá-las com menor força. Nos falta também dizer que a posição de Pereira fica perto de uma abordagem recente da história da geografia francesa, que contesta o lugar-comum da escola vidaliana como geralmente "estrangeira" ao colonialismo de Marcel Dubois. Estes novos estudos dão conta de que as posições foram complexas, e que as questões coloniais tinham uma influência importante sobre toda a geografia dessa época (Clerc, 2011 ; Deprest, 2009).

Segundo Nunes Pereira, enfim, a concepção de Nação de Vidal de la Blache, fundada sobre critérios societários e nas noções de liberdade e justiça, espontaneamente escolhidas pelos povos, diverge do critério racial e linguístico, o que poderia "colocar" a França do Leste em mãos dos alemães - brilhante percepção que Pereira reproduz. Ou mesmo, a ideia de que a França deve estreitar seus laços com a Rússia na direção de encontrar o caminho para a dita Eurásia, reflete da mesma maneira as disputas estatais encetadas em face da Alemanha, que pretende monopolizar, segundo Vidal, esse conjunto de relações.

Como destacado pelos organizadores, esta obra aparece no $120^{\circ}$ aniversário das Annales de Géographie, revista vidaliana que começou suas publicações em 1892. Enquadra-se, nós acrescentamos, na situação brasileira atual, que vive um desenvolvimento dos estudos geográficos e também da história da geografia. ${ }^{2}$

${ }^{2}$ Vea-se o site da Rede Brasileira de Geogrfia Historica e Historia da Geografia http://redebrasilis.net/ 
Pode-se dizer que a geografia ensinada nas universidades é enriquecida com contribuições ao estilo do que foi brilhantemente ensaiado neste esforço de traduções e comentários. Nesse sentido, a seleção que os autores agora vertem ao português, ainda que não tenha sido de todo desconhecida da cultura acadêmica brasileira, são ventos de renovação no debate brasileiro contemporâneo sobre a formação da geografia francesa, da qual as escolas formadas no Brasil são bastante tributárias.

\section{BIBLIOGRAFIA}

CLERC, P. (2011) Tous colonialistes? Les géographes français et l'idéologie coloniale, Communication au colloque Quand l'injustice crée le droit, Archives départementales de Loire-Atlantique, http://www.loireatlantique.fr/upload/docs/application/pdf/2012-

06/clerc_tous_colonialistes.pdf

DEPREST, F. (2009), Géographes en Algérie (1880-1950), savoirs universitaires en situation coloniale, Paris, Belin.

HAESBAERT, R.; NUNES PEREIRA, S.; RIBEIRO, G. (dir.), (2012), Vidal, Vidais: textos de Geografia Humana, Regional e Política, Rio de Janeiro, Bertrad Brasil, 464 p.

MUCCHIELLI L., ROBIC, M.-C. (1995) Entre sociologie et géographie : la morphologie sociale selon Durkheim. In: BORLANDI M., MUCCHIELLI L. (eds.), La sociologie et sa méthode: les règles de Durkheim un siècle après, Paris, L'Harmattan, pp. 101-136.

OZOUF-MARIGNIER, M.-V. (2000) Le Tableau et la division régionale : de la tradition à la modernité. In : ROBIC, M.-C. (ed.), Le Tableau de la Géographie de la France de Paul Vidal de la Blache: dans le labyrinthe des formes, Paris, CTHS, pp. 151-181.

PROCHASSON, Ch. (1997) Histoire et sociologie: Henri Berr et les durkheimiens. In : BIARD A., BOUREL D., Bria E. (eds.) Henri Berr et la culture du XXe siècle, Paris, Albin Michel, pp. 61-79.

ROBIC, M.-C. (2000) Territorialiser la nation. Le Tableau entre géographie historique, géographie politique et géographie humaine. In : ROBIC, M.-C. (ed.), Le Tableau de la Géographie de la France de Paul 
Vidal de la Blache : dans le labyrinthe des formes, Paris, CTHS, pp. 183225.

Robic, M.-C. (2004) Un système multi-scalaire, ses espaces de référence et ses mondes. L'Atlas Vidal-Lablache. Cybergeo: European Journal of Geography, Dossiers, Journée à l'EHESS. Échelles et territoires, Paris, 29 avril 2002, http://cybergeo.revues.org/index3944.html

ROBIC, M.-C. (2009) De la relativité ... Élisée Reclus, Paul Vidal de la Blache et l'espace-temps. In : BORD, J.-P. (ed.) et alii, Élisée Reclus Paul Vidal de la Blache: Le Géographe, la cité et le monde, hier et aujourd'hui. Autour de 1905, Paris, L'Harmattan, pp. 305-314.

Larissa Alves de Lira

Federico Ferretti 